TM-1665

\title{
Vacuum Deposition System
}

\author{
Sharon Austin and Dan Bark \\ Fermi National Accelerator Laboratory \\ P.O. Box 500 \\ Batavia, Illinois 60510
}

May 31, 1990 


\section{VACUUM DEPOSITION SYSTEM}

Sharon Austin and Dan Bark

The Physics Section vacuum deposition system is available for several types of thin film techniques. Examples of the uses for the system are:

1. Evaporated coatings of the wave shifter, p-Terphenyl, on photomultiplier tubes, as done for E687, E690, and E769.

2. Aluminum thin film coatings on:

a. Individual fibers for CDF prototypes.

b. Whole small calorimeters for E774.

c. 1400 angstrom coatings on mylar for small foil cathodes for E769.

3. Mirror coatings of Aluminum, thickness between 700 to 1000 angstroms, and overcoated with Magnesium Floride for beam line detectors.

4. Gold evaporated for foils for beam position detectors for Loma Linda.

5. Other materials evaporated:
a. Cesium Iodide
b. Copper
c. Nickel Chrome

This vacuum evaporation system operates in the high vacuum range. The evaporation source is a resistive heating element, either a boat or a filament design. Coating is then line of sight from the source. Substrates to be coated can have a maximum diameter of 17 inches. At this time the variations in the thickness of the coatings can be controlled, by monitor, to within about 100 angstroms. The system diagrams follow the Operation Procedures and the Sample Coating Procedures. (See Figs. 1, 2, and 3.) 


\section{Calculating Film Thickness}

with

\section{Crystal Monitor}

$T_{f}=\left(1.02 \times 10^{-8}\right)\left(f_{q}-f\right) / P_{f}$

$T_{\mathrm{f}}=$ Film thickness

$f_{q}=$ Unloaded crystal frequency

$f=$ Loaded crystal frequency

$P_{f}=$ Film density

\section{Tooling Factor}

$T F=\left(x_{c} / x_{s}\right)^{2}$

$X_{c}=$ Sensor distance to boat

$\mathrm{X}_{\mathrm{s}}=$ Substrate distance to boat

\section{Sample - Aluminum Coating}

$$
\begin{aligned}
& T_{f}=\text { Thickness desired }=800 \text { Angstroms }\left(8 \times 10^{-6} \mathrm{~cm}\right) \\
& P_{f}=\text { Aluminum density }=2.7 \mathrm{~g} / \mathrm{cm}^{3} \\
& 8 \times 10^{-6}=\frac{\left(1.02 \times 10^{-8}\right)(f)}{2.7} \\
& f=\text { frequency needed }(T F=1) \\
& \text { ie. } X_{c}=X_{s} \\
& f=21.18 \mathrm{Khz}
\end{aligned}
$$


Vacuum Deposition System Operation

I. Initial start-up.

A. Main circuit breaker on back side of vacuum cart.

1. Be sure Bleed-up Valve is closed.

2. Switch breaker on for entire system power.

3. Roughing pump now on (larger belt driven pump ).

B. Valve Logic switch, on separated control panel, to on.

C. With Throttle Valve turned all the way in (clockwise for closed), By-pass toggle switch down (off), and Diffusion pump Isolation Valve turned all the way in (closed clockwise), switch the Fore-Pump (diffusion pump backing pump) to on (smaller belt driven pump).

D. When both the roughing pump and the fore-pump are pumping quietly, the diffusion pump may be switched on, only if it is to be used, as it uses heated oil to trap molecules.

II. Pumping Down.

A. To open the system to the roughing pump use the white rocker switch on the vacuum cart.

1. Off is the centered position.

2. On is the Test position.

3. Vent is rarely used on this system, it allows small amounts of air into the system.

B. Be sure Bleed-up valve is closed.

C. Check that the 275 Convectron gauge read-out is operating.

D. Do not turn on the Penning guage until the convectron gauge reads $1 \mathrm{mTor} r(10-3)$.

E. Now to pump down.

1. White rocker switch on (test) position.

2 . Should see a rapid fall in pressure in the vacuum tank as read on the convectron gauge.

3. If using diffusion pump.

a. To pump down on the cold trap.

1) Set By-pass toggle switch to on (up).

2) Slowly open the Throttle valve by turning it out (counter clockwise).

3) Should see a rise in pressure then a rapid fall as more of the system is pumped down.

b. Gauge should read below $50 \mathrm{mTorr}$.

1) Tank and cold trap are at the same stage.

2) Switch the By-Pass switch to off to isolate the cold trap and diffusion pump.

c. Diffusion pump should have had 20 minutes of preheating time and should be hot to the touch.

1) Open the Diffusion Pump Isolation Valve slowly (counter clockwise). 
2) Allow the combination of the diffusion and the fore-pump to pump on the cold trap for 3-5 minutes.

3) Diffusion pump system is now ready to be used.

4) Liquid nitrogen is not added until the diffusion pump is opened to the entire tank.

4. Switch By-Pass Toggle Switch up, to open the valve, so that the diffusion pump is now seeing the vacuum tank.

a. There should be a drop in pressure as seen by the digital readout gauge. indicating the diffusion pump is working.

b. Wait for a few minutes for system to stablize. Then add Liquid Nitrogen to the cold trap, slowly.

c. When the vacuum level drops to $10 \mathrm{mTorr}$ or less the roughing pump should be valved out of the system, to prevent oil backing into system.

d. Set the white rocker switch to the center position to shut the valve electronically and isolate the roughing pump.

III. Pump to required vacuum level for type of coating required.

A. Maintain the coldtrap.

1. Fill with LN2 two times a day.

2. Trap has a maximum capacity to last 18 hours.

3. Do not let cold trap warm up while diffusion pump is working.

B. System vacuum level is at $1 \mathrm{mTorr}$.

1. Penning gauge can be turned on.

2. High vacuum readings of better than $10-3$.

3. Do not leave the Penning gauge on while coating.

C. See "Sample Aluminum Coating Procedure" 
Sample Aluminum Coating Procedure

I. To open vacuum tank.

A. Switch By-Pass Toggle switch off (down) to valve, electronically, the diffusion pump out so no air enters that area.

B. Set white Rocker switch to center position to valve the roughing pump out so no air enters.

C. Be sure Penning Gauge is off.

D. For cleanest tank care use Nitrogen gas to bleed up the system. Attach to Bleed-up Valve and open slowly. Convectron Gauge should read at atmosphere to open tank.

II. For simple Aluminum coating.

A. Use pure Aluminum wire, $99.99 \%$ pure, as the evaporant.

B. Use a Tungsten boat as material holder, another option for aluminum is to use the tungsten filament carrier.

1. The boat type holders are more directional and potentially give thicker coatings.

2 . The filament type carrier evaporates more quickly in all directions and gives thinner films that are smoother and more reflective.

C. It is important to maintain clean surfaces for good vacuum work.

1. The copper electrodes should not have a build up of various evaporated materials.

2 . The boat and aluminum wire can be cleaned with acetone or freon.

3. Use gloves if possible to protect from hand oils.

D. Mount the boat.

1. Clamp the boat securely between the electrodes.

2. Fill the boat with approximately .4 grams of aluminum wire.

3. Better melting occurs with short pieces in maximum contact with the boat.

E. Mount the substrate.

1. Ideal coating occurs within a 30 degrees off vertical for a 60 degree optimum coating area.

2 . Distance from the boat is variable.

a. Must be far enough above to get entire area, to be coated, within optimum coating angle.

b. Must be far enough away from boat to protect material if it is susceptable to heat.

3. Remember the coating is strictly straight line. Anything in the way will shadow the substrate.

4. Be sure the Thickness Monitor Readout is on and reset to zero by pushing the white button on the front.

5. While resetting note the crystal life reading that appears. If over 120 the gold crystal in the sensor will need to be replaced. 
F. Position the Thickness Monitor Sensor Head.

1. The crystal sensor is mounted on tubing as it can be water cooled if necessary.

2. Ideally the sensor should be the same distance from the boat as the substrate.

3. See attached formula for calculating thickness readings based on evaporant and distance.

G. Lower tank carefully to clear the substrate.

1. Insert shutter mounted on 6 " blank-off flange.

2. Shutter should be positioned above the boat and have space to be pulled back out of the coating path.

3. Use glass view port to do final visual check on coating set up.

H. Pump down (follow system operating instructions)

1. For a simple aluminum coating, not for a mirror quality finish, the vacuum level needs to be no better than $1 \mathrm{mTorr}(10-3)$.

2 . The diffusion pump can be left pumping on the system as long as the cold trap is protecting the pump. The trap will need to be cleaned more frequently.

III. Evaporation run.

A. Watch the thickness monitor and use the glass port to watch the process visually.

B. Turn on the large Hewlett-Packard 1000 Amp Power Supply, be sure the settings are for the maximum voltage and no current.

C. Small Lambda Power Supply is the remote sensing supply that controls the amps delivered by the H.P. supply.

1. Set current limiter to the maximum.

2. Slowly bring up the voltage.

3. Set the voltage on the Lambda to 1.0 .

a. Wait for warm up of boat.

b. Also big H.P. supply has a delay before it delivers the current.

4. After H.P. is reacting set voltage to 1.5 .

a. Watch the boat become hot with a bright orange glow.

b. When aluminum wire is softening it glows and then slumps into boat.

c. Boat will appear to cool at this point.

d. The shutter should still be in place above the boat.

5. Turn the voltage on the Lambda up to about 2.1 .

a. At this point the voltage can be varied between 2.1 and 2.3 (maximum).

b. Finally setting usually is 2.2 volts for ease of coating.

6. Monitor the melting of the aluminum in the boat.

a. Visually you should see the boat glowing very brightly, it can hurt the eyes so it is best to wear protection. 
b. You can see the aluminum melt and pool and then it wets to the sides of the tungsten boat.

c. Also the Thickness Monitor should begin to show that the aluminum is evaporating and some beginning coating is occurring.

7. Pull the shutter back out of the way.

8. The Thickness Monitor should indicate that the coating rate is slowly becoming more rapid.

a. Shut the power off when you have reached the predetermined reading for the thickness required.

b. Shut the power off when the boat is empty.

1) Visually you see that there is no more aluminum wetting the sides of the boat.

2) The Thickness Monitor readings rapidly fall off.

c. Push the shutter in to protect the substrate from residual coating.

IV. Remove the substrate.

A. Switch the By-Pass switch to off and the white rocker switch should be in centered position.

B. Bleed-up the vacuum tank with Nitrogen gas, if possible.

C. Gloves still are recommended for handling. Do not touch the coated area as the coating can be marked.

D. Remember the boat will be warm. 


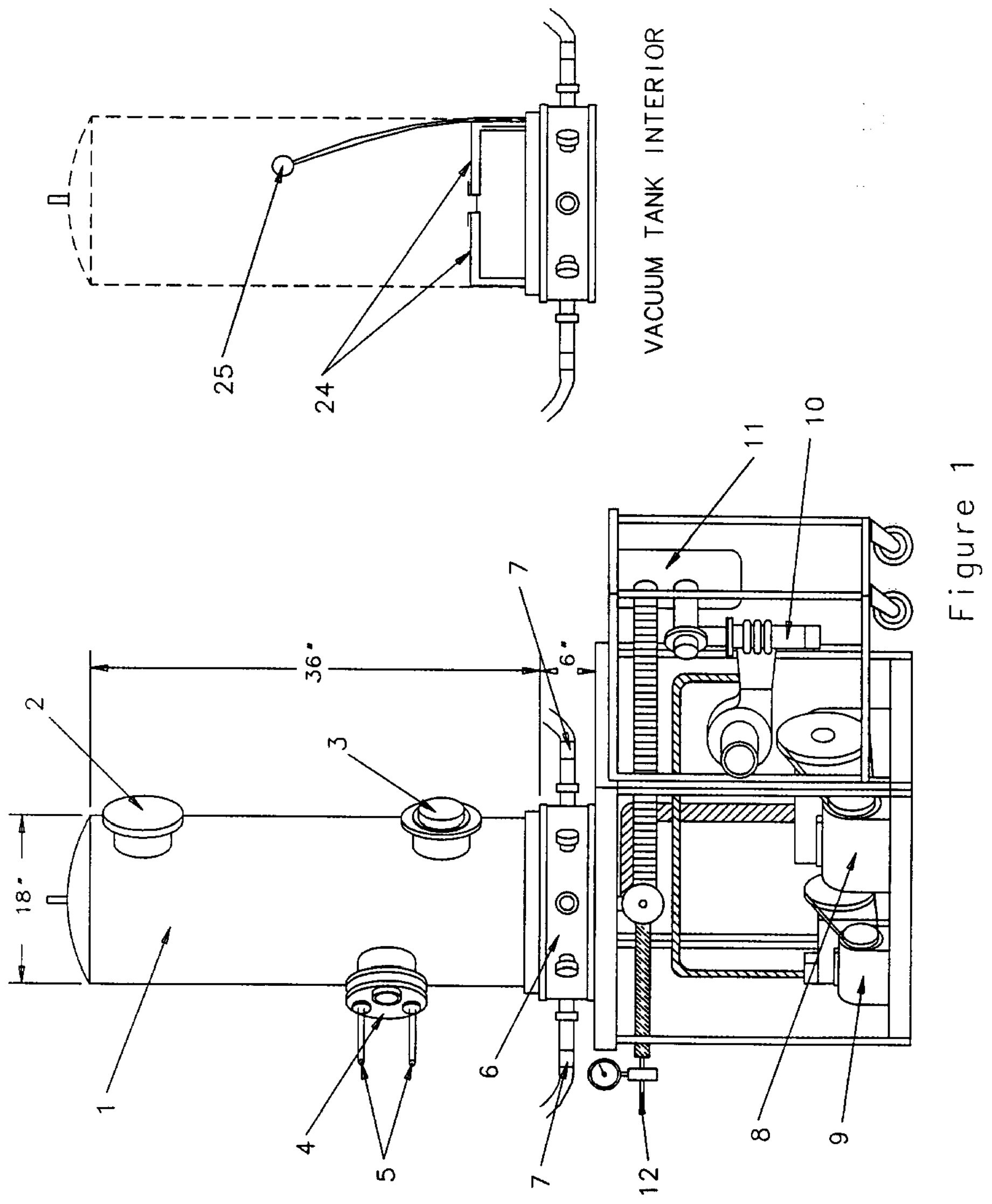




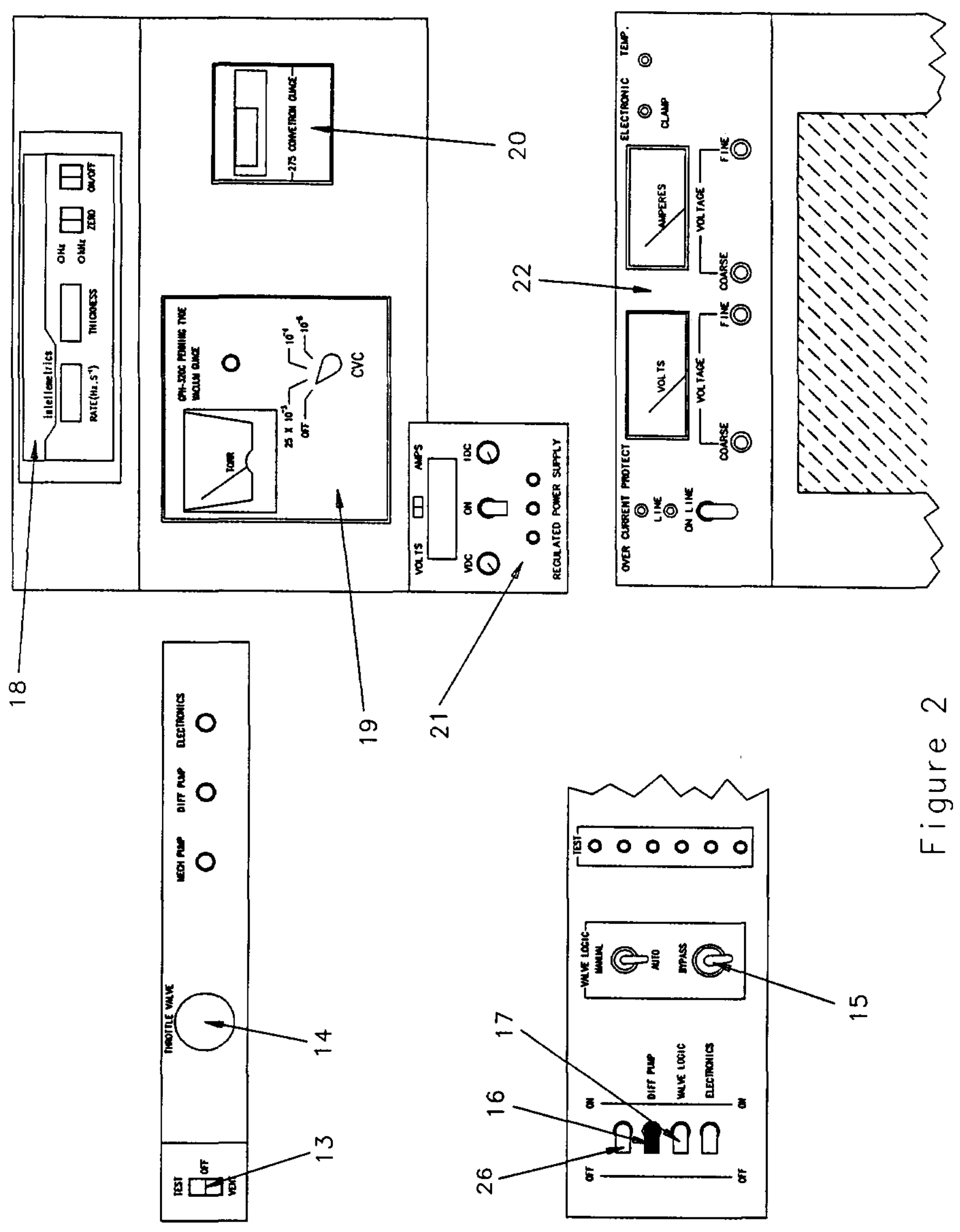




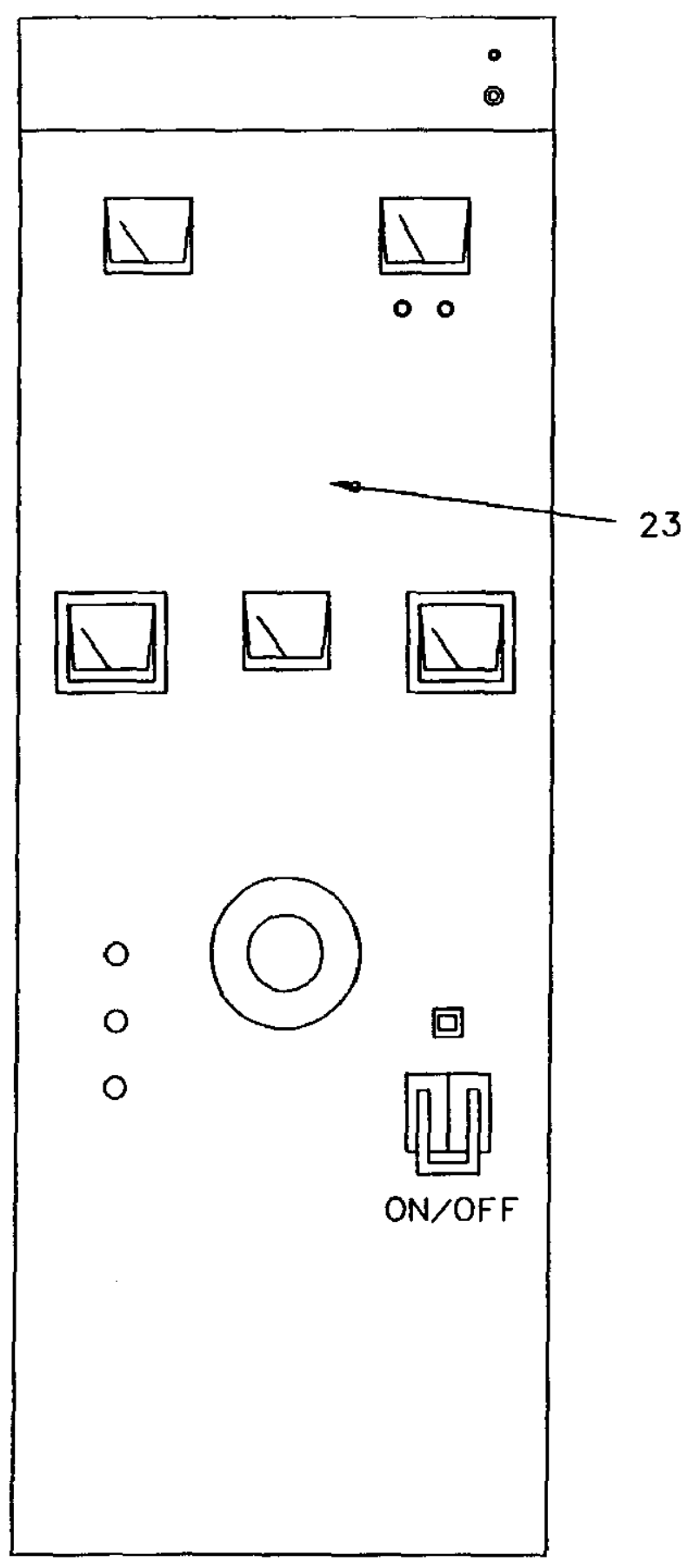

\begin{tabular}{|c|c|}
\hline 1 & BELL JAR \\
\hline 2 & $6^{\circ}$ FEEDTHROUGH \\
\hline 3 & 6* FEEDTHROUGH :GLASS VIEWPORT \\
\hline 4 & $6^{\circ}$ FEEDTHROUGH \\
\hline 5 & ROTARY FEEDTHROUGH FOR SHUTTER \\
\hline 6 & FEEDTHROUGH COLLAR WITH O-RING SEAL \\
\hline 7 & (2) 600 AMP INSULATED CONDUCTORS \\
\hline 8 & ROUGHING PUMP \\
\hline 9 & FORE PUMP (BACKING FOR DIFFUSION PUMP) \\
\hline 10 & DIFFUSION PUMP \\
\hline 11 & COLD TRAP $\mathrm{LN}_{2}$ \\
\hline 12 & BLEED-UP VALVE \\
\hline 13 & ROUGHING PUMP VALVE SWITCH \\
\hline 14 & THROTTLE VALVE \\
\hline 15 & BYPASS, ELECTRICALLY ACTS AS THROTTLE VALVE \\
\hline 16 & DIFFUSION PUMP OFF/ON-HEATING \\
\hline 17 & VALVE LOGIC-ALL ELECTRONIC VALVES OFF/ON \\
\hline 18 & THICKNESS MONI TOR \\
\hline 19 & PENNING VACUUM GUAGE, READOUT \\
\hline 20 & CONVECTRON VACUUM GUAGE, READOUT \\
\hline 21 & LAMDA LQ410 POWER SUPPLY;REMOTE SENSING \\
\hline 22 & 6464C DC H.P. POWER SUPPLY 0-1000 A (MAX 8V) \\
\hline 23 & TALL 150A POWER SUPPLY \\
\hline 24 & COPPER ELECTRODES \\
\hline 25 & SENSING HEAD FOR THICKNESS MONITOR \\
\hline 26 & FOREPUMP ON/OFF \\
\hline
\end{tabular}

NOTE: TURBO PUMP IS ATTACHED AS NEEDED

Figure 3 